\title{
GBEP
}

\section{Formação de professores e profissionalização: contribuições dos estudos publicados na Rbep entre 1998 e 2011}

Bernardete A. Gatti

\section{Resumo}

Apresenta uma análise dos trabalhos sobre formação de professores e aspectos de sua profissionalização, publicados pela Revista Brasileira de Estudos Pedagógicos em 22 números editados entre 1998 e 2011, perfazendo 38 artigos, classificados e estudados em sete subtemas, a saber: história da educação; política de formação e contexto social; formação inicial e profissionalização docente; formação a distância; trabalho docente; formação continuada; temas variados. Verifica-se que a contribuição dos artigos é altamente relevante, trazendo perspectivas de compreensão da formação e do trabalho docente sob diversas óticas, o que é o papel da pesquisa, e, com isso, favorecendo que gestores possam se apropriar desses conhecimentos para o delineamento e implementação de políticas nessa área. Restam as questões do diálogo entre gestores e a pesquisa educacional.

Palavras-chave: Revista Brasileira de Estudos Pedagógicos; formação de professores; licenciaturas; trabalho docente; educação básica. 


\section{Abstract \\ Teacher's education and professional development of teachers: contributions of studies published by the Revista Brasileira de Estudos Pedagógicos - 1998-2011}

This paper presents an analysis of a set of studies about teacher's education and professional development of teachers published by Revista Brasileira de Estudos Pedagógicos, which brought together 38 articles in 22 editions from 1998 to 2011. All of them were classified and studied under seven sub-themes: history of education; education policies and social context, initial education and professional development of teachers, distance education, teacher's work; ongoing education and also varied themes. As a result, it was identified a wide contribution of those articles on teacher's education and teacher's work, adding comprehension under several points of view which, by the way, it is the role of research, allowing the appropriation of these knowledge by managers for the design and also implementation of policies in such area. There still remain the issue of dialogue between managers and educational research.

Keywords: Revista Brasileira de Estudos Pedagógicos; teacher's education; teacher's work; basic education.

Nas duas últimas décadas, no Brasil, esforços foram concentrados na área educacional, tendo no seu horizonte os desafios postos pelas demandas e necessidades que emergiram em nossa sociedade em várias frentes - necessidades de ordem social, econômica e cultural que se colocam no contexto dos direitos humanos.

No setor educacional, em suas várias instâncias nos governos, procurou-se: reorganizar aspectos do financiamento da educação; aumentar os anos de escolaridade da população; investir em infraestrutura; orientar os currículos da educação básica; ampliar as oportunidades no ensino superior; formar docentes por diversos meios; deslocar a formação dos professores da educação básica do nível médio para o nível superior; desenvolver programas de formação continuada de professores; melhorar os livros didáticos e sua distribuição; orientar a elaboração de planos de carreira docente; instituir o piso salarial nacional para professores, entre tantas outras ações políticas.

Nestes últimos cinco anos, muito especialmente, a preocupação com políticas dirigidas aos docentes da educação básica passou ao primeiro plano, levando à implementação de vários programas específicos, tanto em nível federal como em Estados e muitos municípios, estes mobilizados 
por questões regionais próprias ou estimulados pela ação do Ministério da Educação (Gatti; Barretto; André, 2011).

A formação inicial de professores nas licenciaturas é tema que começa a suscitar intensos debates. O trabalho docente, as carreiras e salários, a identidade profissional de professores e sua formação continuada e as práticas docentes na educação de crianças e adolescentes são questões que têm preocupado pesquisadores, gestores da educação e amplos segmentos sociais. Na esteira de discussões de associações e sindicatos, de organizações diversas e da mídia, esses temas adquiriram relevância política e social no contexto dos debates em torno da qualidade da educação escolar no País. Portanto, formação e trabalho de docentes é tema da maior importância na atualidade brasileira.

\section{Corpus e metodologia}

O corpo de análise do presente estudo é composto por 38 artigos sobre o tema da formação de professores, publicados na Revista Brasileira de Estudos Pedagógicos (Rbep) do no 193 ao no 231, perfazendo 22 números. Buscou-se, inicialmente, ter uma visão geral dos artigos, por título e resumo e por várias leituras dos textos. Procedeu-se, a partir disso, a uma classificação dos trabalhos em função do problema específico abordado, categorizando-os em sete subtemas (Quadro 1) e distribuindo as temáticas tratadas por ano de publicação (Quadro 2).

Quadro 1 - Classificação dos Artigos Publicados na Rbep sobre o Tema Formação e Profissionalização de Professores, por Subtema - 1998-2011

\begin{tabular}{|c|c|c|}
\hline Subtema & $\mathbf{F}$ & Números \\
\hline História da Educação & 1 & 193 \\
\hline Política de Formação e contexto social & 4 & $\begin{array}{l}194-198-200- \\
219\end{array}$ \\
\hline $\begin{array}{l}\text { Formação inicial e } \\
\text { Profissionalização docente }\end{array}$ & 12 & $\begin{array}{l}198-203-209(2)- \\
220-226(2)-227(2) \\
-228-230-231\end{array}$ \\
\hline Formação a distância & 2 & $200-218$ \\
\hline Trabalho docente & 11 & $\begin{array}{l}215-216-219-221 \\
-223-224-225- \\
226-227-230-231\end{array}$ \\
\hline Formação continuada & 4 & $217(2)-225-230$ \\
\hline Outros temas & 4 & $197-215-225-231$ \\
\hline Total & 38 & \\
\hline
\end{tabular}


Quadro 2 - Classificação dos Subtemas Tratados nos Artigos da Rbep sobre o Tema Formação e Profissionalização Docente, por Ano - 1998-2011

\begin{tabular}{|c|c|c|}
\hline Ano & $\mathbf{F}$ & Subtemas Tratados \\
\hline 1998 & 1 & História da Educação \\
\hline 1999 & 1 & Política de Formação e Contexto Social \\
\hline 2000 & 3 & $\begin{array}{l}\text { Política de Formação e Contexto Social } \\
\text { Formação Inicial e Profissionalização } \\
\text { Outros temas }\end{array}$ \\
\hline 2001 & 2 & $\begin{array}{l}\text { História da Educação } \\
\text { Formação a Distância }\end{array}$ \\
\hline 2002 & 1 & Formação Inicial e Profissionalização \\
\hline 2004 & 2 & Formação Inicial e Profissionalização \\
\hline 2006 & 5 & $\begin{array}{l}\text { Trabalho Docente } \\
\text { Formação Inicial e Profissionalização } \\
\text { Outros temas }\end{array}$ \\
\hline 2007 & 3 & $\begin{array}{l}\text { Formação a Distância } \\
\text { Formação Inicial e Profissionalização } \\
\text { Trabalho Docente }\end{array}$ \\
\hline 2008 & 2 & Trabalho Docente \\
\hline 2009 & 7 & $\begin{array}{l}\text { Formação Continuada } \\
\text { Formação Inicial e Profissionalização } \\
\text { Trabalho Docente } \\
\text { Outros temas }\end{array}$ \\
\hline 2010 & 5 & $\begin{array}{l}\text { Formação Inicial e Profissionalização } \\
\text { Trabalho Docente } \\
\text { Política de Formação e Contexto Social }\end{array}$ \\
\hline 2011 & 6 & $\begin{array}{l}\text { Formação Continuada } \\
\text { Formação Inicial e Profissionalização } \\
\text { Trabalho Docente } \\
\text { Outros temas }\end{array}$ \\
\hline \multicolumn{2}{|c|}{ Total } & 38 \\
\hline
\end{tabular}

\section{Aspectos gerais a ressaltar}

Verifica-se inicialmente, pelo número de artigos publicados, que a questão da formação de professores foi tema sempre presente nas diferentes edições da Rbep no período considerado, embora não tenha sido ela o tema mais abordado. Observando a distribuição dos estudos no tempo, é a partir de 2006 que um maior número de trabalhos relativos à docência é publicado pela Revista. De fato, questões ligadas à formação de professores tendem a emergir como muito importantes a partir da intensificação, nos anos 2000, da discussão quanto à qualidade da educação escolar à luz da disseminação cada vez maior dos dados oriundos das políticas de avaliação do Ministério da Educação (MEC), de vários Estados e de alguns municípios. Essas discussões levantam-se tanto na 
área acadêmica como na política e na própria sociedade de um modo geral. A mídia aumenta sua cobertura quanto aos resultados dessas avaliações, e os desempenhos preocupantes dos estudantes levantam a questão da qualidade da educação escolar pública e acabam por trazer à baila o papel dos professores e sua formação. Mas não só. Trazem também à luz, com força, a condição de seus baixos salários, suas precárias condições de trabalho, a intensificação desse trabalho, os poucos apoios pedagógicos que recebem, os problemas de gestão na educação, a pouca atratividade dessa carreira e as demandas decorrentes das novas condições socioculturais na contemporaneidade (Fanfani, 2007; Freitas, 2007; Duarte, 2008; Gatti et al., 2010; Oliveira, 2010; Gatti, 2010). Há um aumento significativo de trabalhos investigativos na década de 2000 sobre esses problemas, e, com isso, também aumenta o número de pesquisas sobre o tema (André, 2009, 2010). Então, a crescente preocupação com a escolarização das novas gerações no contexto atual caminha par a par com o crescente número de trabalhos sobre a formação e o trabalho docente na educação básica sob diversos ângulos, o que também se encontra refletido nos artigos selecionados para os diversos números da Rbep nesse período. Se nos anos anteriores a 2006 apareciam com maior representação proporcional estudos relativos a políticas de formação e contexto social e estudos com temas variados, a partir desse ano a maior proporção de trabalhos publicados incide sobre a formação inicial e continuada dos professores e o trabalho docente. Nota-se uma preocupação mais direta com a profissionalidade ${ }^{1}$ e a profissionalização dos docentes para o nível básico da educação escolar; ou seja, o aumento do número de artigos publicados na Revista, nesses anos, sobre os elementos intervenientes no exercício da docência na educação básica reflete a crescente preocupação com esse nível de ensino no País, dialogando com as preocupações da sociedade brasileira como um todo.

No contexto desse movimento social, educacional e político, políticas fortes são colocadas em ação pelos órgãos centrais da educação no País e por governos regionais e locais. Embora suas formas de implementação, financiamento e impacto ainda necessitem de avaliações mais precisas, há um realinhamento de programas voltados à docência e a institucionalização em nível federal de um aparato administrativo, técnico e computacional que permite melhor acompanhar, ordenar e relacionar as diferentes ações implementadas.

Os problemas levantados quanto à formação inicial oferecida nas licenciaturas àqueles que serão futuros professores da educação básica e ao atendimento das demandas das redes de ensino por professores levaram à implementação de programas específicos, como o Plano Nacional de Formação de Professores da Educação Básica (Parfor), o Programa Institucional de Bolsa de Iniciação à Docência (Pibid), o Exame Nacional de Concurso de Professores, a oferta de formação em ensino a distância (EaD) pela Universidade Aberta do Brasil (UAB), entre outras iniciativas específicas.

Então, com os movimentos sociais e educacionais nas duas últimas

características de uma profissão que enfeixa um grupo específico de conhecimentos e habilidades necessárias ao exercício profis sional, a base para a profissionalização, o que implica a obtenção de um espaço autônomo, próprio a uma dada profissionalidade com valor claramente reconhecido pela sociedade (Ramalho; Nuñez; Gauthier, 2003). décadas, com a expansão das redes escolares, as avaliações de redes de 
ensino, as pesquisas que vieram levantando problemas sobre a qualidade da educação escolar no Brasil e sobre a formação dos professores e suas condições de trabalho, as discussões públicas ampliadas sobre essas questões, as iniciativas políticas em educação, em diferentes níveis e perspectivas, forma-se um cenário em que emergem problematizações e estudos dos fatores que interferem na qualidade do ensino, entre eles os problemas associados ao exercício da docência na educação básica. Como isso aparece nos estudos publicados na Rbep entre 1998 e 2011?

\section{Problemas abordados nos estudos}

Como já mostrado no Quadro 1, as questões abordadas nos artigos publicados no período em foco, para fins de análise, podem ser agrupadas como tratando de: história da educação; política de formação de professores associada a questões de contexto social amplamente considerado; formação inicial e aspectos da profissionalização dos docentes; formação a distância; trabalho docente; formação continuada; e temas variados. Dois subtemas mostraram-se mais recorrentes: a formação inicial e o trabalho docente. Neste tópico vamos tratar dos estudos dentro de cada agrupamento.

\section{História da Educação}

Apenas um artigo tem como foco aspectos da história da formação de professores no Brasil. O texto de Kulesza (1998) trata da história da institucionalização das escolas normais no Brasil (1871-1910), um estudo detalhado sobre o impacto da reforma Leôncio de Carvalho, de 1879, nas iniciativas de criação de escolas normais por várias províncias. Três formas de institucionalização dessas escolas são apontadas: a primeira, mediante associação aos liceus responsáveis pelo ensino secundário, preparatório para o ensino superior, em formas de acomodação, com um aligeiramento na formação geral e introdução de um ano de formação educacional; a segunda, pela transformação direta do liceu em escola normal; a terceira baseou-se na extensão da escolarização de órfãos entregues a instituições dirigidas por ordens religiosas. Mostrando especificidades e variações entre as províncias, conclui o autor que "as escolas normais, gradativamente, conformam-se aos projetos políticos das oligarquias locais"; também, mesmo com os desejos de renovação após a instalação da República, verifica-se muito mais uma continuidade do que uma ruptura inovadora, e a feminização crescente da clientela, em torno de 1910, "foi muito mais acentuada em detrimento de sua profissionalização" (Kulesza, 1998, p. 69-70).

Os reflexos dessa constituição da formação de professores para os anos iniciais da escolarização e a forma como vai ocorrer na década de 1930 a institucionalização das licenciaturas para formar professores para 
o secundário, como adendo menor dos bacharelados, nos dizem bem da imagem precária que politicamente norteou essa formação. Essa postura até hoje se reflete na estrutura e dinâmica das instituições formadoras de professores: de um lado, uma perspectiva formativa genérica e fragmentada, e, de outro, foco em conhecimentos específicos, mais do que para a docência (Gatti, 2010). Isso sinaliza a força de uma tradição cultural conservadora que não se abre para rupturas e reorganizações significativas, questão que deveria ser cuidada com maior intensidade pelos gestores públicos responsáveis pela estrutura e dinâmica dessa formação e pelas instituições formadoras. A questão da inovação na formação de professores para a educação básica, como veremos adiante, é preocupação mundial. Muitas iniciativas existem em outros países procurando atualizar essa formação em maior consonância com as necessidades sociais e culturais que a sociedade contemporânea coloca, o que tem levado a reestruturações profundas nessa formação. Permanecemos com uma estrutura formativa que pode ser qualificada como arcaica, e, ainda, temos aligeirado essa formação, quer em termos de currículo, quer em termos de duração da formação - não nos faltam estudos e pesquisas mostrando essas fragilidades, mas faltam políticas públicas mais fortes nesse ponto (Gatti; Barretto, 2009).

\section{Política de formação e contexto social}

O estudo de Bragança (2001) traz ao leitor aspectos da docência nos anos 1960, por meio de uma análise de artigos publicados na própria Rbep nesse período, buscando "capturar lampejos do passado" (p. 7) em fase tensa na sociedade brasileira, procurando com isso estruturar imagens da docência nesses anos. Mostra a importância dos referentes históricos em sua relação com conjunturas contextuais para a constituição da imagem do ofício de professor. Se conjugarmos o que o artigo de Kulesza (1998) nos trouxe com este de Bragança, embora reflitam dois momentos diferentes da história da constituição do profissional docente, ambos mostram o peso da tradição histórico-cultural e das relações sociais e econômicas reificadas em situações específicas. Nessa tradição, observa-se, de um lado, os interesses de hegemonias dominantes na estruturação da formação de professores e, de outro, uma cultura que favorece tanto a manutenção de um modo de formação clássico de inspiração positivista ${ }^{2}$ como a distância

${ }^{2}$ Foi significativa a influência de Benjamin Constant na estrutura dessa formação. Professor positivista da Escola Politécnica do Rio de Janeiro, ele assumiu a direção da Escola Normal do Rio de Janeiro em $1880(\mathrm{Ku}-$ lesza, 1998). Lembremos que a institucionalização da formação de professores "primários" precedeu a institucionalização da formação específica de professores secundários. Mas a lógica foi semelhante em ambos os casos. máticas da pesquisa educacional em relação à escola básica e, também, a sua não validação social como fator a considerar dentro dessas posturas. A separação social, acadêmica e de trabalho do intelectual e do executor interpõe barreiras ao trânsito mais fluente entre teoria e prática. Embora com metodologias e focos diferentes, ambos mostram com muita acuidade os arranjos político-práticos em termos de conveniência momentânea na institucionalização da formação de professores para a educação inicial, criando uma situação histórica de precarização formativa, como também 
mostram a constituição do distanciamento entre teoria e prática, ligada, em suas origens, a uma conformação de classe social, real ou virtual, na separação dos que pensam e dos que executam.

Os outros três artigos desta categoria percorrem o período de 1999 a 2007. A discussão feita por Valente (1999) converge com os problemas trazidos por Kulesza e Bragança. Trata dos desafios postos às universidades pela Lei de Diretrizes e Bases da Educação Nacional (LDB - Lei $n^{\circ}$ 9.394/1996), que coloca a formação de professores em Institutos Superiores de Educação, nas universidades ou fora delas, mostrando a preocupação político-acadêmica com essa inovação no cenário educacional brasileiro e as resistências a ela. Artigo bem situado no tempo histórico, contextualiza no cenário nacional a questão da formação de professores, ressaltando o que já vinha sendo colocado nos artigos até aqui citados: o alerta constante de educadores e pesquisadores quanto à necessidade de reformulação integral desses cursos, o que não ocorreu nas épocas anteriores (e não ocorre até hoje). Sua análise leva à conclusão de que o mais importante seria que as lideranças educacionais se preocupassem mais com as características dessa formação do que com o lugar em que ela se dá. Postula que as universidades deveriam se dedicar mais à questão da formação dos professores, sendo as pontas de lança de inovações e não reprodutoras de um modelo arcaico, já superado. Caberia às universidades, assim, criar espaços institucionais de interlocução entre as diversas licenciaturas, construindo projetos pedagógicos para esses cursos sob um "novo paradigma, onde conteúdo específico e pedagógico, ensino e pesquisa, teoria e prática se articulem de forma coerente, consistente e comprometida" (Valente, 1999, p. 76), tendo como princípio básico o diálogo, o que considera difícil nas estruturas acadêmicas vigentes.

Com outros argumentos, os ensaios de Pereira et al. (2000) e Vilela (2007) acabam por propugnar também por mudanças nas formações de docentes, considerando o cenário pós-industrial contemporâneo. Pereira et al. refletem sobre a formação de professores à luz das colocações de Habermas, considerando as transformações do mundo do trabalho na atualidade. No quadro traçado, reflete que, se aspectos de conservação são importantes para a preservação social e, portanto, para a educação, também se colocam como importantes as inovações e, assim, "a formação do educador precisa levar em conta a racionalidade técnica (saber ensinar um conteúdo, o processo), o desenvolvimento da subjetividade e a razão crítica" (Pereira et. al., 2000, p. 214). Mudanças substantivas serão necessárias à formação de professores, de tal forma que propicie um espaço de desenvolvimento de novas habilidades cognitivas e sociais para que um salto qualitativo seja possível na formação das novas gerações.

Vilela (2007) parte de uma perspectiva sobre a sociedade contemporânea colocada como dominada pela visão gerencialista, voltada a processos e produtos, mas demandando flexibilidade e mobilidade, repleta de incertezas morais e científicas, e inserida em uma nova complexidade tecnológica. No contraponto desse movimento da sociedade, há reações para a permanência de estruturas, paradigmas e formas de controle. Com base em 
autores consagrados, como Baumann, Lyotard, Morin e outros, coloca a tensão existente na sociedade contemporânea e seu impacto no trabalho dos professores. Põe em evidência situações de ansiedade e conflito entre identidade, mobilidade e mudança - nas condições de trabalho, nos currículos, nas formas de controle. Realça que um desafio se situa no envolvimento dos professores com processos de mudança em sua esfera de ensino para atender à qualidade da educação requerida pela sociedade contemporânea. Para tanto uma nova formação é requerida, visto que "a mudança no trabalho docente ainda tem se mantido de forma superficial e não tem atingido o cerne da questão" (Vilela, 2007, p. 240).

\section{Formação inicial de professores e profissionalização docente}

Incluímos aqui artigos que tratam de aspectos da formação inicial de professores na graduação (licenciatura). Um único artigo se reporta a uma proposta e experiência formativa em nível médio (publicado no $n^{\circ}$ 198), o que se relaciona com a mudança gradativa do nível de formação de professores para o ensino superior proposta na Lei no 9.394/1996. Há um artigo que apresenta uma análise de iniciativas mundiais para o aperfeiçoamento da formação inicial de professores, dando uma visão mais ampla da questão no mundo. Contam-se nesta categoria, ao todo, 12 artigos, a maioria publicada a partir de 2006.

As colocações trazidas pelos artigos já apresentados nos dois primeiros subtemas de que tratamos, segundo as quais renovações ou inovações são absolutamente necessárias na formação de professores no Brasil, também aparecem expressas nas pesquisas ou reflexões relatadas nos artigos que tratam diretamente de aspectos da formação inicial de professores nas licenciaturas, aí incluída a pedagogia.

Todos apresentam pesquisas ou baseiam-se em pesquisas já realizadas para desenvolver uma nova análise. Grosso modo, podemos encontrar nesse grupo de artigos duas abordagens: um conjunto que analisa novas formas de ação em currículo/disciplinas ou estágios nas licenciaturas, em busca de inovação, estudando seus efeitos; outro conjunto que busca compreensão sobre fatores que permeiam concepções/representações sobre a formação e a profissão docente.

No primeiro conjunto - pesquisas sobre práticas inovadoras -, salientamos que os fundamentos e discussões sobre as ações empreendidas e estudadas, via pesquisa-ação ou pesquisa qualitativa, mostram-se colocadas com um sentido cultural amplo e com finalidades formativas humanísticas, tendo o nível de ensino a que se refere como foco. Não se mostram sob uma ótica tecnicista, reducionista. Este aspecto é um diferencial relevante desses trabalhos, pois se colocam como proposições indicativas, sugestivas, e não como receitas prontas, tendo seus autores a postura de analisar tanto os processos e resultantes positivos como os problemas, impasses e desafios encontrados nas realidades das instituições e cursos. Abordam-se: 
- situações de trabalho formativo com desenho e arte e sua interface com a alfabetização de crianças;

- o uso de casos de ensino para desenvolvimento de processos de aprendizagem profissional docente;

- formas de análise de processos de aprendizagem de professores em formação, numa perspectiva construtivista, que os ajudam a transformar conhecimentos teóricos e práticos, tratados no curso, em ferramentas para organização de seu trabalho pedagógico;

- trabalho com pesquisa em formação docente;

- estudo sobre o emprego da Metodologia da Problematização em estágios curriculares de curso de licenciatura;

- estudo sobre a contribuição formativa para licenciandos de um estágio coletivo, considerando o impacto dos conhecimentos prévios no desenvolvimento de práticas em sala de aula;

- análise de implementação de programa curricular inovador em licenciaturas, desde o processo de construção institucional e coletiva do programa até os processos curriculares realmente desenvolvidos: princípios e objetivos, organização e articulação das diferentes licenciaturas, estrutura mínima comum, componentes da mesma e estágio supervisionado, atividades acadêmico-científico-culturais.

Verifica-se, com esses estudos, que há ricas contribuições para a formação de licenciandos articulando, de fato, teoria e prática, pesquisa e ação pedagógica, podendo ser tomados como referência para outras instituições e situações formativas iniciais de professores, bem como para políticas.

No segundo conjunto - compreensão sobre concepções/representações sobre a formação e a profissão docente - encontram-se pesquisas qualitativas que permitem lançar luz sobre o imaginário e as representações ou concepções de formandos de cursos de Pedagogia, os quais têm papel de significação e de condicionamento de ações em situações reais. Somos seres interpretativos, e nossas interpretações dirigem nossas ações, nosso trabalho. As pesquisas relatadas mostram que o conhecimento desse imaginário, dessas representações, pode fundamentar novas modalidades para a formação docente considerando as motivações mais profundas dos estudantes na área e sua interpretação de situações e processos educacionais. Nessa linha há ainda estudo representacional com ex-licenciandos sobre o papel da pesquisa da prática pedagógica como elemento formador para a docência, que aporta compreensão sobre essa prática em currículo de licenciatura levantando seus aspectos contributivos a novas compreensões sobre o ensinar e lança luz sobre as contradições e problemas gerados em uma dada condição institucional. A análise de trajetórias de formação e de vida de estudantes de Pedagogia levanta o papel das subjetividades, em suas constituições sociais e culturais, na construção de conhecimentos e identidades profissionais.

Um estudo teórico especificamente voltado para as áreas tecnológicas e científicas sob inspiração da Conferência Nacional de Ciência, Tecnologia 
e Inovação, realizada em 2001, põe em questão, argumentativamente, o perfil de formação dos licenciandos para essas áreas e pontua o atraso de setores científicos em se preocupar com reformular essa formação e até com a própria formação, não atentando para o risco de o Brasil se tornar em futuro próximo um "excluído" tecnológico e científico por não ter massa crítica de professores para a formação das novas gerações, visto que as crianças na educação básica não estão sendo preparadas nem estimuladas para o conhecimento nesses setores. Professores bem formados para isso são necessários. Sem base e motivação para o estudo das ciências, haverá obstáculos para a formação de um maior número de pessoas dedicadas ao trabalho científico e tecnológico, o que limitará nossa projeção nesse cenário.

O artigo de Vaillant (2010) destaca os problemas encontrados na América Latina quanto à formação de professores e coloca que a pergunta importante a ser feita hoje é: Para onde vai a formação de professores? Com essa questão em mente, percorre experiências dos Estados Unidos, da Austrália, da Inglaterra, da Holanda, da Finlândia e da Suécia. Esses países têm procurado sistematicamente introduzir inovações na formação de seus professores, claro que dentro de suas características sociopolítico-culturais específicas. Importante é que essas experiências mostram ser possível melhorar a formação dos docentes, sobretudo por meio de uma maior vinculação dessa formação com as escolas e a pesquisa e reflexão vinculadas às práticas educacionais. Além disso, apontam para a necessidade de políticas sistêmicas, inter-relacionadas, com durabilidade no tempo, e de uma política consistente de avaliação das instituições formadoras que permita retroalimentar os processos formativos. Assim, essas iniciativas merecem um olhar porque delas podemos tirar inspirações. A primeira talvez seja a de que precisamos mudar as práticas relativas à nossa proposta de avaliação das instituições formadoras e respectivos cursos de licenciatura.

\section{Formação a distância}

Apenas dois artigos entraram nesta categoria, talvez porque, para muitas instituições, a grande expansão e ampliação dos cursos da formação de professores a distância esteja ocorrendo somente nos últimos três anos. Um dos artigos foi publicado em 2001, momento em que iniciativas de caráter especial $^{3}$ de formação a distância ou semipresencial de docentes para a educação básica já haviam sido realizadas ou estavam em pleno andamento (nos Estados de Mato Grosso, São Paulo e Minas Gerais, notadamente, além do projeto Proformação, do MEC). O segundo foi publicado em 2007, em outro momento das políticas educacionais, quando já havia sido promulgada a equivalência dos cursos a distância aos presenciais e já estavam em franco crescimento autorizações do Conselho Nacional de Educação (CNE) para a oferta dessa modalidade de curso (Gatti; Barretto; André, 2011).

${ }^{3}$ Foram implantadas com autorização especial do Conselho Nacional de Educação ou dos Conselhos Estaduais de Educação, com vigência delimitada. 
Preti (2001) discute em seu artigo os novos contornos da formação de professores em função das perspectivas de EaD, faz uma retrospectiva histórica dessa modalidade formativa e analisa a experiência pioneira do Núcleo de Educação Aberta e a Distância (NEaD) da Universidade Federal do Mato Grosso (UFMT). Destaca como fatores importantes na consolidação do projeto formativo dessa iniciativa: os cuidados no delineamento do projeto e na constituição da equipe de formadores e técnicos; o próprio modelo tal como foi realizado, dentro das condições do Estado; as parcerias com o governo e a Universidade Estadual; a institucionalização dos Centros de Apoio e dos Núcleos Municipais de Educação a Distância, entre outros. A institucionalização segura e suficientemente amadurecida foi fator determinante para os resultados positivos alcançados. Nas conclusões, enfatiza que as formas de ação desenvolvidas no NEaD/UFMT permitiram uma reconstrução de práticas e uma ressignificação de discursos, lembrando que "os movimentos de renovação pedagógica ou de inovações educativas e de expansão da EaD não podem ser percebidos ou analisados como sendo determinados por simples 'diretrizes governamentais', resultado da vontade dos governantes, pois estão enraizados na cultura e experiências locais... Buscam a consolidação de novos valores..." (Preti, 2001, p. 37).

O artigo de Cunha e Vilarinho (2007) é uma revisão de literatura no que se refere à formação a distância na educação continuada de professores, com os objetivos de identificar os focos de estudo e as questões mais recorrentes nos trabalhos analisados. Mostrou que, neles, o foco mais privilegiado é o das políticas públicas nesse nicho, destacando-se a preocupação com políticas aligeiradas de formação a distância e certificação em escala. Há proposições de como melhorar essa oferta com a discussão de seus pontos frágeis e sugestões de novas formas de implementação e avaliação dessas iniciativas. Outros estudos que atualizam a revisão da literatura sobre essa questão evidenciam que pesquisas continuam apontando a questão do aligeiramento formativo e da falta de monitoramento dos programas de EaD na formação de docentes para a educação básica e as fragilidades em seus modelos de institucionalização, sobretudo no que se refere à tutoria (Gatti; Barretto, 2009; Gatti; Barretto; André, 2011).

\section{Trabalho docente}

É interessante notar que apenas a partir de 2006 aparecem, no período considerado, artigos sobre as questões do trabalho docente e da vida de professor. São 11 artigos que tratam dessa questão sob diversos ângulos. Problemas associados ao trabalho docente têm sido objeto de vários estudos, mas não só: as discussões se ampliaram para o âmbito social e político, com as lutas da categoria por melhores salários e carreira e por melhores condições para o trabalho de ensino, o trabalho nas escolas (Barbosa, 2011). Os artigos publicados na Rbep, até aqui, não 
adentram nas questões das políticas de carreira e salário, mas, sim, tratam, sobretudo, de tensões e crises no trabalho cotidiano nas escolas, nas condições em que estas se institucionalizam em diversas redes de ensino. A questão dos movimentos do social e da economia na contemporaneidade, as mudanças culturais e de valores sociais, as pressões por desempenho e produtividade, as necessidades de atualização constante, flexibilidade social e didática, fluidez organizacional e os novos comportamentos das crianças, adolescentes e jovens são fatores analisados na determinação das imagens, representações e percepções sobre o trabalho docente, condições essas que geram tensões constantes no exercício profissional. Compõem o quadro da atividade dos professores não só essas fontes de tensão e dilemas, mas também as frustrações geradas, as dificuldades no equacionamento do trabalho nos tempos escolares e com as características dos alunos e a burocracia das redes, bem como a fragmentação e a contradição produzida nas relações entre tempo profissional e tempo pessoal. O trabalho do professor não se esgota na escola: faz-se presente o tempo todo, em cada dia dos professores, em tarefas externas à escola e em preocupações que não se trancam na saída da escola. Há uma intensificação nesse trabalho que nem sempre é considerada, uma vez que demanda investimento pessoal alto. Entende-se porque alguns artigos de pesquisa publicados na Rbep sinalizam como o sentido de dedicação aparece como eixo da profissão - o interesse pessoal e afetivo - mais do que o lógico e o econômico, evocando-se a aptidão como forte fator para a escolha e permanência na profissão. Para professores, a imagem de si como profissional ancora-se em uma razão de vida (carisma), e, diante de suas realidades cotidianas, geram-se contradições pessoais que permeiam sua dedicação, desânimo ou desistências (Alves-Mazzotti, 2008; Pereira; Andrade, 2006).

Há um trabalho dedicado à formação de professores para EJA em que se procura comparar pesquisas sobre a questão no Brasil e na Argentina. Verifica-se que há raros estudos sobre a questão, embora ela esteja muito presente nos discursos das políticas educacionais e nos documentos de gestão e financiamento.

Um dos artigos aborda especificamente o trabalho docente do professor formador de professores, aquele que, no ensino superior, trabalha nas licenciaturas (André et al., 2010). A pesquisa relatada mostrou que as novas características dos estudantes nas licenciaturas e os contornos de algumas políticas educacionais e de situações nas instituições formadoras evidenciam a necessidade mais que urgente da reestruturação dos modelos formativos aí desenvolvidos. Conclui que, "confrontados com a necessidade de preparar para a docência os jovens que chegam hoje à universidade, com um perfil muito diferente do esperado, os formadores se encontram diante do dilema de formar esse 'aluno possível' para uma 'docência possível', nas situações concretas do trabalho nas escolas" (p. 140). Os projetos institucionais não incorporam mudanças substantivas que respondam ao desafio das características dos estudantes que buscam as licenciaturas e deixam aos seus docentes a tarefa de enfrentar as dificuldades daí decorrentes. Ressaltando 
as dificuldades geradas no trabalho dos professores formadores de professores para a educação básica, pelas condições socioculturais de seus alunos e a não preocupação institucional e de políticas com essa questão, mais uma vez nos defrontamos aqui com o grave problema da formação de docentes para a educação básica.

Os egressos das licenciaturas, ao adentrarem na profissão, viverão experiências nas escolas que, em continuidade à sua formação inicial, lhes propiciarão ir completando sua condição de profissional do ensino. Ambrosetti e Almeida (2009) relatam pesquisa que mostra a formação da profissionalidade docente no espaço escolar, nas experiências nas escolas, onde se processa uma reconfiguração de concepções iniciais sobre o trabalho de ensino pela atuação de fatores institucionais diversos e diferentes entre si, fatores pessoais-relacionais e outros. Segundo as autoras, a compreensão dessas aprendizagens em situação cotidiana de trabalho pode subsidiar processos formativos para o trabalho docente com fundamentos socioantropológicos que não podem ser negligenciados, visto que a educação escolar é processo social de intensas relações humanas presenciais numa dada cultura - a de uma sociedade e a de uma escola em uma determinada rede de ensino, com suas características próprias.

Finalmente, trazemos o estudo de Diniz-Pereira (2011) que discute os sinais de crise na profissão docente no Brasil argumentando na direção da conjunção de diferentes fatores constituintes dessa crise - ou seja, há múltiplas causas para ela: salários compatíveis, dedicação exclusiva a uma única escola, tempo para planejamento didático e estudos, salas de aula e número de alunos adequados, etc. Não dá para assumir que apenas a má formação dos docentes é responsável pelos problemas na escolarização (posição, em geral, das Secretarias de Educação) nem que eles são apenas vítimas de uma situação social e educacional (posição dos sindicatos). Pondera que este tipo de polarização não ajuda a compreender todas as interfaces relativas ao trabalho docente e à crise que se sinaliza na profissão e até contribui para que não se avancem soluções para essa situação.

Como se vê, há uma rica contribuição para o conhecimento e a reflexão sobre as condições de trabalho dos professores, suas motivações, dificuldades, crises e mobilizações possíveis. São contribuições que podem sustentar boas políticas de ação e práticas de gestão. Resta querer e, assim, conseguir traduzi-las.

\section{Formação continuada}

Nos estudos sobre trabalho docente encontramos conhecimentos que tangenciam a formação continuada em serviço. Os quatro artigos classificados nesta categoria, no entanto, focam diretamente essa questão. São relatos e análises de experiências de formação continuada em redes de ensino, realizadas por professores de universidade em integração com as escolas. Um deles pesquisa o papel da utilização de casos de ensino 
nessa formação e seus efeitos positivos na conscientização de processos formativos; essa metodologia permite aos professores analisar seus modos de trabalhar o ensino da língua escrita e a iniciação à matemática, refletir sobre sua própria formação profissional, redirecionar ações buscando fundamentar seus conhecimentos pedagógicos gerais, os de conteúdos específicos, conhecimentos pedagógicos associados aos conteúdos, levantando lacunas e motivando a sua superação. O segundo artigo mostra e analisa um programa de educação continuada de uma universidade discutindo sua validação. O terceiro, a partir de trabalho com professores e coordenadores pedagógicos, acompanhando os módulos produzidos para o curso desenvolvido, procura verificar aspectos do multiculturalismo em propostas didáticas e curriculares concretas, bem como analisar as formas de construção e reconstrução identitária dos envolvidos na proposta. E o quarto aprofunda estudo sobre duas formas de trabalho com professores em uma rede municipal de ensino - oficinas de currículo integrado e laboratório de vivências pedagógicas -, trazendo evidências de seu impacto positivo na utilização da experiência empírica para ações planejadas e metodologicamente pensadas e organizadas. Houve contribuição também para o aumento do interesse e motivação dos professores pela busca de soluções para atividades de ensino, aumentando sua crença em sua própria capacidade de criar alternativas de trabalho (Neitzel; Mafra, 2011).

Nas discussões da literatura educacional sobre formação continuada de professores encontra-se apontada a importância de essa formação estar ancorada nas realidades educacionais das redes de ensino e das escolas, nas experiências específicas dos docentes, para ter significado e impacto formativo relevante (Falsarella, 2004; Placco; André; Gatti, 2003; Duarte, 2006; Calderano; Lopes, 2006). Os artigos publicados na Rbep, aqui apontados, avançam contribuindo para a compreensão de como processos de formação continuada de professores desenvolvidos a partir dessas ideias surtem efeitos significativos para os participantes, sem deixar de apontar questões que surgem e necessitam de novos equacionamentos.

\section{Temas variados}

Assuntos diversos são abordados nos artigos aqui incluídos, seja em forma de ensaio, seja através de pesquisa. Há uma discussão alentada sobre uma questão que toca em aspecto cultural no cenário educacional brasileiro, que é a da moda ou modismo na oposição velho/novo, causando perturbações nas práticas e na formação dos docentes. Adesões forçadas, ou adesões acríticas, ou adesões genéricas ou formais a imposições de "inovação" e desprezo ao que mal havia mostrado sua contribuição ao trabalho escolar são eventos correntes em nossas políticas e práticas educacionais, o que provoca impasses, estagnações e/ou resistências que acabam por prejudicar o trabalho escolar e a própria aprendizagem e desempenho dos alunos. Uma perspectiva mais objetiva e mais solidamente fundamentada quanto a essa tendência a modismos é necessária 
nas gestões educacionais e pedagógicas. Conclui-se que "a mentalidade que rejeita estudar o passado, ou que o estuda com as viseiras de gurus, é a grande adversária da compreensão do presente e dos esforços que empreendemos para tentar mudar a escola atual" (Rosso; Mafra, 2000, p. 62).

Os demais artigos tratam, na sequência temporal de publicação: de uma pesquisa sobre o perfil de professores do primeiro ciclo do ensino fundamental quanto ao tipo de práticas adotadas, sinalizando algumas mudanças quanto à incorporação do trabalho coletivo e a disposição física das salas de aula (Macedo e Mortimer, 2006); de um estudo sobre as marcas de profissionais liberais que se tornaram referência na docência no ensino superior, mostrando como os estudantes nas áreas aplicadas valorizam a inserção profissional do docente, suas metodologias, atitudes e posturas pessoais (Volpato, 2009); e, da questão da autoridade docente analisada a partir de fala de alunos de escola pública, verificando-se que a autoridade em sala de aula não mais se assenta na tradição, na submissão a uma autoridade formal, mas em relações bem conduzidas na interlocução intergeracional, no contexto das finalidades do trabalho escolar, uma relação de negociação em que o conhecimento do docente e da docência têm papel central (Bueno e Santana, 2011).

\section{A título de fechamento}

Considerando as contribuições dos artigos analisados, os quais trazem com ênfase a necessidade de mudanças nas formações de professores para a educação básica em consonância com as novas formas de sociabilidade e trabalho, podemos destacar alguns aspectos:

1) pesquisas e estudos sinalizam fortemente que as estruturas formativas de professores no Brasil são arcaicas e superadas e necessitam de sofrer mudanças radicais em função dos movimentos no social emergentes no século 21;

2) a formação de professores para as ciências é ponto nevrálgico e pode comprometer o futuro científico e tecnológico do País;

3) verifica-se que há experiências e estudos trazendo ricas contribuições para a formação de licenciandos, inovando e articulando, de fato, teoria e prática, pesquisa e ação pedagógica, podendo ser tomados como referência para outras instituições e situações formativas iniciais de professores;

4) políticas sistêmicas, integradas e duradouras, bem monitoradas, são urgentes e necessárias no que se refere à formação de docentes;

5) é preciso considerar a mudança nas características socioculturais dos que buscam as licenciaturas, gerando ações institucionais que permitam favorecimentos formativos a esses estudantes e apoios aos formadores de professores;

6) formação a distância requer metodologias específicas e forte apoio infraestrutural e didático, formação adequada de tutores e renovação constante a partir de avaliações eficazes; 
7) práticas inovadoras em educação continuada foram realizadas e analisadas, oferecendo repertório para repensar as políticas e práticas vigentes;

8) é preciso mudar as práticas relativas à nossa proposta de avaliação das instituições formadoras e dos cursos de licenciatura;

9) utilizar mais e melhor o conhecimento e a reflexão sobre as condições de trabalho dos professores, suas motivações, dificuldades, crises e mobilizações possíveis, considerando que esse conhecimento pode sustentar boas políticas de formação e de ação e práticas de gestão.

Como se observa, há muitas e ricas contribuições para a compreensão de aspectos pertinentes da formação de professores para a educação básica e para a profissionalização docente. A pesquisa educacional sobre a docência avançou muito em relação ao que é o seu papel específico: lançar luz sobre os vários fatores intervenientes na formação e no exercício da docência na educação básica. As contribuições aí estão, e os artigos publicados na Rbep atestam isso.

Fica evidente que os artigos acrescentam vários ângulos relativos às questões levantadas, trazendo contribuições para se pensar, repensar e estruturar novas políticas de ação para a superação da problemática condição da docência na educação básica. Desenvolver políticas de ação é o papel dos gestores, responsáveis pelas diversas políticas educacionais. Resta a pergunta: Os executivos em cargos políticos, que devem orientar, gerir e qualificar a educação escolar, serão suficientemente sensíveis e preparados para atentar e se apropriar dessas contribuições e desenvolver e implementar políticas educacionais condizentes com as necessidades de mudança nessa área social tão crucial para o País? A contribuição dos pesquisadores está posta e socializada. Os idealizadores e executores responsáveis pelas políticas de ação na educação tomam ciência dessa contribuição? Conseguem ou conseguirão levá-las em conta devidamente?

\section{Referências bibliográficas}

ALTOBELLI, C. C. A. As dificuldades e queixas de professores alfabetizadores em tempo de formação continuada. 2008. Dissertação (Mestrado em Educação/Psicologia da Educação) - Pontifícia Universidade de São Paulo (PUC-SP), 2008.

ALVES-MAZOTTI, A. J. Representação do trabalho dos professores das séries iniciais: a produção do sentido de "dedicação". Revista Brasileira de Estudos Pedagógicos, Brasília, v. 89, n. 223, p. 522-534, set./dez. 2008.

AMBrosetTI, N. B.; ALMEIDA, P. C. A. Profissionalidade docente: uma análise a partir das relações constituintes entre os professores e a 
escola. Revista Brasileira de Estudos Pedagógicos, Brasília, v. 90, n. 226, p. 592-608, set./dez. 2009.

ANDRÉ, M. E. D. A. de. A produção acadêmica sobre formação docente: um estudo comparativo das dissertações e teses dos anos 1990 e 2000. Formação Docente: Revista Brasileira de Pesquisa sobre Formação de Professores, Belo Horizonte, v. 1, n. 1, p. 41-56, ago./dez. 2009.

. Formação de professores: a constituição de um campo de estudos. Educação, Porto Alegre: PUC-RS, v. 33, n. 3, p. 174-181, set./dez. 2010.

ANDRÉ, M. E. D. A. de et al. O trabalho docente do professor formador no contexto atual das reformas e das mudanças no mundo contemporâneo. Revista Brasileira de Estudos Pedagógicos, Brasília, v. 91, n. 227, p. 122-143, jan./abr. 2010.

BARBOSA, A. Os salários dos professores brasileiros: implicações para o trabalho docente. Brasília: Liber Livro, 2011. 208 p.

BRAGANÇA, I. F. de S. Algumas imagens sobre docência e formação na década de 60: revisitando a Revista Brasileira de Estudos Pedagógicos. Revista Brasileira de Estudos Pedagógicos, Brasília, v. 82, n. 200/201/202, p. 7-14, jan./dez. 2001.

BUENO, F.A.; SANTANA, R.B. A experiência geracional na fala de alunos de escola pública: a questão da autoridade docente. Revista Brasileira de Estudos Pedagógicos, Brasília, v. 92, n. 231, p.316-340, maio/ago. 2011.

CALDERANO, M. da A.; LOPES, P. R. C. (Org.). Formação de professores no mundo contemporâneo: desafios, experiências e perspectivas. Juiz de Fora: Ed. UFJF, 2006.

CUNHA, M. L. da; VILARINHO, L. R. G. Formação continuada de professores a distância: o desvelamento de focos de estudo expressos em produções acadêmicas. Revista Brasileira de Estudos Pedagógicos, Brasília, v. 88, n. 218, p. 76-106, jan./abr., 2007.

DINIZ-PEREIRA, J. E. O ovo ou a galinha: a crise da profissão docente e a aparente falta de perspectiva para a educação brasileira. Revista Brasileira de Estudos Pedagógicos, Brasília, v. 92, n. 230, p. 34-51, jan./abr. 2011.

DUARTE, A. M. C. Trabalho docente na educação básica: novas configurações e formulações teórico-conceituais. In: SEMINARIO DA REDE LATINO-AMERICANA DE ESTUDOS SOBRE TRABALHO DOCENTE - Rede Estrado, 7., 2008, Buenos Aires. Anais... Buenos Aires: Rede Estrado, 2008. 1 CD-ROM. 
DUARTE, V. de C. Uma experiência de educação continuada em Juiz de Fora-MG. In: CALDERANO, Maria da Assunção; LOPES, Paulo R. Curvelo (Org.). Formação de professores no mundo contemporâneo: desafios, experiências e perspectivas. Juiz de Fora-MG: Ed. UFJF, 2006.

FALSARELLA, A. M. Formação continuada e prática de sala de aula: os efeitos da formação continuada na atuação do professor. Campinas: Autores Associados, 2004.

FANFANI, E. T. Consideraciones sociologicas sobre profesionalización docente. Educação \& Sociedade, Campinas, v. 28, n. 99, p. 335-353, 2007.

FREITAS, H. C. L. A (nova) política de formação de professores: a prioridade postergada. Educação \& Sociedade, Campinas, v. 28, n. 100, p. 1203-1230, out. 2007. Especial.

GATTI, B. A. Formação de professores no Brasil: características e problemas. Educação \& Sociedade, Campinas, v. 31, n. 113, p. 1355-1379, out./dez. 2010.

; BARRETTO, E. S. S. Professores do Brasil: impasses e desafios. Brasília: Unesco, 2009.

; BARRETTO, E. S. S.; ANDRÉ, M. E. D. A. Políticas docentes: um Estado da Arte. Brasília: Unesco, 2011.

KULESZA, W. A. A institucionalização da Escola Normal no Brasil: 1870-1910. Revista Brasileira de Estudos Pedagógicos, Brasília, v. 79, n. 193, p. 63-71, set./nov. 1998.

MACEDO, M.S.A.N.; MORTIMER, E.F. Perfil de professores do primeiro ciclo: questões socioculturais e pedagógicas. Revista Brasileira de Estudos Pedagógicos, Brasília, v. 87, n. 215, p.29-43, jan./abr. 2006.

NEITZEL, A. A.; MAFRA, C. Formação continuada para professores da educação básica: metodologia do currículo integrado e laboratório de vivências pedagógicas. Revista Brasileira de Estudos Pedagógicos, Brasília, v. 92, n. 230, p. 52-69, jan./abr. 2011.

OLIVEIRA, D. A. La construcción política de la profesión docente: la experiencia brasileña. In: OLIVEIRA D. A. et al. (Org.). Políticas educativas y territórios: modelos de articulación entre niveles de gobierno. Buenos Aires: IIPE/Unesco, 2010. p. 131-158.

PEREIRA, W. C. et al. A formação dos formadores em face dos novos conceitos da produção no contexto da globalização. Revista Brasileira de Estudos Pedagógicos, Brasília, v. 81, n. 198, p. 209-218, maio/ago. 2000. 
PEREIRA, G. R. de M.; ANDRADE, M. C. L. de. Lucro de ação: um exame das condições de possibilidade do magistério oficial. Revista Brasileira de Estudos Pedagógicos, Brasília, v. 87, n. 215, p. 9-18, jan./abr. 2006.

PLACCO, V. N.; ANDRÉ, M. E. D. A. de; GATTI, B. A. Proformação: avaliação do programa. Brasília: MEC, 2003. Relatório Técnico.

PRETI, O. A formação de docentes na modalidade a distância: (des) construindo metanarrativas e metáforas. Revista Brasileira de Estudos Pedagógicos, Brasília, v. 82, n. 200/201/202, p. 26-39, jan./dez. 2001.

RAMALHO, B. L.; NUÑEZ, I. B.; GAUTHIER, C. Formar o professor, profissionalizar o ensino. Porto Alegre: Sulina, 2003.

ROSSO, A. J.; MAFRA, N. D. F. Entre o perene e o novo: a arte de compreender o modismo educacional. Revista Brasileira de Estudos Pedagógicos, Brasília, v. 81, n. 197, p. 50-83, jan./abr. 2000.

VAILLANT, D. Iniciativas mundiales para mejorar la formación de profesores. Revista Brasileira de Estudos Pedagógicos, Brasília, v. 91, n. 229, p. 543-561, set./dez. 2010.

VALENTE, S. M. P. Institutos Superiores de Educação: desafios para as universidades. Revista Brasileira de Estudos Pedagógicos, Brasília, v. 80, n. 194, p. 71-80, jan./abr. 1999.

VILELA, E. C. As interferências da contemporaneidade no trabalho docente. Revista Brasileira de Estudos Pedagógicos, Brasília, v. 88, n. 219, p. 229-241, maio/ago. 2007.

VOLPATO, G. Marcas de profissionais liberais que se transformaram em professores-referência. Revista Brasileira de Estudos Pedagógicos, Brasília, v. 90, n. 226, p. 333-361, maio/ago.2009.

Bernardete Gatti é doutora em Psicologia - Université de Paris VII Université Denis Diderot, com pós-doutorados na Université de Montréal e na Pennsylvania State University. Docente aposentada da USP, foi professora do Programa de Pós-Graduação em Educação: Psicologia da Educação da PUC-SP e exerceu a função de superintendente de Educação e Pesquisa da Fundação Carlos Chagas (FCC). Atualmente, tem atuado como pesquisadora colaboradora na FCC e como consultora de instituições nacionais e internacionais.

gatti@fcc.org.br 